Article

\title{
Impact of Agricultural Labor Transfer and Structural Adjustment on Chemical Application: Comparison of Past Developments in the Ecological Civilization Pilot Zones of China and Their Future Implications
}

\author{
Hua Lu, Hualin Xie * (1), Qianru Chen and Jinfa Jiang \\ Institute of Ecological Civilization, Jiangxi University of Finance and Economics, Nanchang 330013, China; \\ luhuanj@126.com (H.L.); cqrjufe@163.com (Q.C.); overseas@jxufe.edu.cn (J.J.) \\ * Correspondence: xiehl_2000@163.com; Tel.: +86-139-7912-1643
}

Received: 14 March 2018; Accepted: 6 June 2018; Published: 7 June 2018

\begin{abstract}
Reducing the application of agricultural chemicals is a key point in promoting the construction of an ecological civilization and the green development of the agricultural sector. Based on statistical yearbook data from provinces which became the first national ecological civilization pilot zones in China, this paper quantitatively analyzes the impact of labor transfers and structural adjustment of agriculture on the application of agricultural chemicals by using comparative analysis and a panel data model. The results show that the amplitude of the agricultural labor force in Fujian, Guizhou, and Jiangxi decreases successively. The planting structure adjustment for grain crops is slowest in Jiangxi, while the sown area of cash crops, such as vegetables, increases at the fastest rate in Guizhou. The increase of horticultural plants, such as orchards is the most obvious in Jiangxi. The application of agricultural chemicals grows quickly. The influence of the agricultural labor force scale on the application of fertilizers and pesticides is statistically significantly negative. The ratio of the sown area of non-grain crops to the total sown area has a positive effect on the application of fertilizers and pesticides. In the context of the continuing agricultural labor transfer in China, combining the structural adjustment of agriculture and the supply of high-quality agricultural products, the government should actively guide and support new agricultural business entities in applying organic manure. Additionally, it should accelerate the development of smaller agricultural machinery that can be used for smaller land areas and by elderly people to reduce the application of chemical fertilizer and pesticide.
\end{abstract}

Keywords: agricultural chemicals; environmental management; agricultural structural adjustment; labor transfer; ecological civilization pilot zone; China

\section{Introduction}

China is vigorously promoting the construction of an ecological civilization at present. Ecological civilization is a social form based on the basic aim of harmonious coexistence of man and nature, man and man, as well as man and society. It is the sum of material, spiritual and institutional achievements that mankind has acquired in order to protect and build a good ecological environment. In 2016, "Comments on the Establishment of a Unified and Standardized National Ecological Civilization Pilot Zone" pointed out that, "to improve the level of resource utilization and eco-environmental quality, select provinces with good ecological basis and strong resource and environment carrying capacity as the first batch of areas included in National ecological civilization pilot zone, namely, Fujian Province, Jiangxi Province and Guizhou Province." On 2 October 2017, the general office of the Communist Party of China (CPC) and the general office of the State Council issued "the Implementation 
Plan of National Ecological Civilization Pilot Zone (Jiangxi Province)," as well as one for Fujian Province. So far, the implementation plans for the first national ecological civilization pilot zones in Fujian, Guizhou and Jiangxi in China have been announced. The implementation plans for the three provinces have both similarities and differences. On 18 October 2017, the report of the 19th National Congress of the CPC pointed out the need to "accelerate the reform of ecological civilization system, and provide more high-quality ecological products to meet people's growing needs for a beautiful ecological environment." The construction of an ecological civilization emphasizes the coordinated development between the economy and resources, and it is necessary to cope with the relationship between development and ecological environmental protection correctly.

Agriculture not only depends on, but also influences, the ecological environment. Agricultural production and the environment are compatible [1,2]. However, to ensure the supply of agricultural products, such as grain, the intensive use of cultivated land and overuse of agricultural chemicals, such as fertilizers and pesticides, has led to serious environmental problems, such as the over-farming of cultivated land, over-exploitation of groundwater, heavy metal pollution in soil, degradation of the ecological environment [3,4], and an increase in the agricultural non-point source pollution [2]. As a result, the constraints of the agricultural resource environment are tightening and the situation of the agro-ecological environment is worsening. Labor transfers and structural adjustments of agriculture are currently the two main characteristics of agricultural development in China. Additional ones include the important opportunities to improve the agricultural ecological environment and to promote the green production of agricultural products.

With the acceleration of urbanization in China, agricultural labor transfer is inevitable. The "Report on China's Migrant Population Development 2016" pointed out that, during the 13th Five-Year Plan, urban and rural population migration will remain active. By 2020, China's floating population is estimated to increase to 291 million, and the total agricultural transfer population will reach 220 million. Family migration will also increase [5]. According to the theory of induced institutional innovation [6-8], the scarcity of agricultural labor will induce farmers' rational adjustment of factor structure and planting structure and savings of relatively scarce productive resources to minimize costs and maximize profits [9-12] (according to United Nation International Labor Organization, workers aged 45 and above are defined as older workers. Census data for 1990, 2000 and 2010 shows that, the proportion of agricultural labor aged 45 and above in China was $22.7 \%, 35 \%$ and $47.1 \%$ respectively. The aging trend of the agricultural labor force is obvious. Data from the second agricultural census shows that the female agricultural workforce accounted for $53.16 \%$ of the total agricultural workforce, which is more than the male workforce). Some researchers believe that farmers can cope with the effect of labor transfer through strategies, such as increased investment in alternative elements and reconfiguration of the labor force devoted to grain and non-grain crops $[13,14]$. Labor transfer also restricts the supply of agricultural labor. Driven by time constraints and economic interests, farmers no longer abide by traditional, intensive, and meticulous farming methods. Instead, they have developed an over-reliance on modern techniques, such as chemical fertilizers, to increase output, leading to rising fertilizer consumption [15-17]. Farmers also tend to reduce the frequency of application and increase the amount of fertilizer applied each time to save labor costs, and avoid output loss and risks [18-21]. Loss of the family labor force decreases the farmers' labor input for grain production, but strengthens their investment in capital-intensive crops [22]. More and more land will be used to plant more profitable cash or feed crops, which require more fertilizers [23,24]. Moreover, seasonality in agricultural production strengthens the labor constraint in season, and it is difficult to use agricultural machinery in these provinces because of the terrain restrictions in hilly and mountainous areas $[25,26]$. As such, traditional agricultural production modes, such as extensive management of agriculture and intensive use of fertilizers and pesticides, is inevitable $[27,28]$. In additional, the credit and insurance markets are not perfect in rural areas in China, and farmers realize self-financing and self-insurance by means of migration, which strengthens the accumulation of productive assets of farmers in Mexico [29-31]. Farmers also have the tendency to expand livestock breeding and engage in risker business activities in Albania because labor transfer 
leads to higher incomes [32]. Remittances generated by labor migration promoted an increase in the proportion of farmers planting high value-adding economic crops [33]. Additionally, the remittances reduce the financial constraints on farmers purchasing agricultural production materials and brings about more fertilization [34,35]. At the same time, the transfer of the rural labor force will likely lead to the development of new agricultural business entities and differentiation among rural households, which will, in turn, lead to changes in farmers' factor input structure and agricultural production modes $[15,17,36]$. To gain higher profits from agricultural operations, new agricultural business entities will, for instance, change traditional agricultural production modes and create new ones, moving from chemical agriculture - which mainly depends on fertilizers and pesticides—-to organic green agriculture [37-39].

Fujian, Jiangxi, and Guizhou are endowed with good ecological bases and strong environment carrying capacity, but the application of agricultural chemicals, such as fertilizers and pesticides, is increasing. It has become a prominent problem with regard to agricultural ecological resources, and such negative influences on the agricultural environment will gradually increase in these provinces. Therefore, in 2017, the Ministry of Agriculture in China issued the "Notice on the Implementation of the Five Actions of Agricultural Green Development." In the notice, it is required that the utilization rate of fertilizers and pesticides is targeted to be over $40 \%$, and the recycling rate of agricultural film over $80 \%$ (the utilization rate of fertilizers refers to the proportion of fertilizers deposited on targets per unit area of the total amount of fertilizers used (i.e., deposition rate). In general, the whole field crop is regarded as a target, and the part of the fertilizers deposited on the crop is considered to be an effective quantity. The recycling rate refers to the ratio of agricultural films that has been recycled and continued to used, to the total agricultural film). Fertilizer applied to cultivated land per hectare had exceeded the global average and optimal dosage, and was still increasing in China [40]. "Agricultural Modernization Planning (2016-2010)" in China pointed out that the fertilizer utilization rate for main crops in China in 2015 was 35.3\%. Moreover, the inefficient and over-use of fertilizer is a prominent problem. Reducing the application of agricultural chemicals is key to promoting agricultural green development, and an important characteristic of the national ecological civilization pilot zone.

China is vigorously promoting the construction of an ecological civilization. Current agricultural development in China is characterized by labor transfer and the structural adjustment of agriculture. It is foreseeable that, in current trends of rural reform and urbanization in China, a large number of the rural labor force will transfer to urban and non-agricultural sectors continuously in the near future. The agricultural environment will be threatened by the massive non-agricultural labor supply from rural areas. With the acceleration of economic development and construction of an ecological civilization in China, agricultural environmental problems caused by farmers' behavior will receive more and more attention. The three provinces of the first national ecological civilization pilot zone, namely, Fujian, Jiangxi, and Guizhou, are large-scale labor-exporting provinces. The development of pilot zone may be can provide paths and relevant experiences for sustainable development of agriculture in other regions. As such, this paper attempts to answer the following questions:

(1) How did labor transfer, structural adjustment and the application of agricultural chemicals develop in these three provinces?

(2) How and to what extent did labor transfer and structural adjustment of agriculture in the three provinces influence the application of agricultural chemicals?

Quantitative analysis on the relationship among the three provinces helps promote the agricultural modernization and sustainable development of agriculture in the ecological civilization pilot zone. It may provide some implications for agricultural development, which matches with agricultural productivity and environment carrying capacity. The structure of the paper is as follows: First, we comparatively analyze the status of labor transfer, structural adjustment of agriculture, and the application of agricultural chemicals by using statistical yearbook data from the three provinces which became the first national ecological civilization pilot zones in China. Second, we theoretically 
summarize the possible mechanism of labor transfer and structural adjustment on agricultural chemical application, and propose a model for the empirical analysis. Finally, we describe the results, and present conclusions and a discussion.

\section{Labor Transfer, Structural Adjustment, and Application of Agricultural Chemicals in Fujian, Jiangxi, and Guizhou}

\subsection{Labor Transfer}

From the perspective of agricultural labor resources (Table 1), the three provinces have seen a continuous decline in the scale of agricultural labor. During 2001-2012, the agricultural labor force in Fujian and Jiangxi declined from 7.604 million and 9.494 million to 6.149 million and 8.41 million, a decrease of $19 \%$ and $11 \%$, respectively. In Guizhou, the agricultural labor force declined from 13.683 million in 2001 to 11.653 million in 2011, a decrease of $15 \%$ within 10 years. Fujian had the smallest agricultural labor force scale, but it appeared to decline the most. Guizhou had the largest agricultural labor force, but its decreasing amplitude was greater than in Jiangxi, which witnessed the slowest decreasing amplitude. The declining agricultural labor force brings a decrease in labor supply as follows: the transfer of rural young people and the shift of a relatively high-quality labor force to non-agricultural industries leads to the aging of the agricultural labor. Since older workers do not know how to use small or simple agricultural machinery, especially when agricultural machinery suitable for hilly and mountainous farming is deficient, they will tend to apply fertilizers and pesticides to make up for the shortage of machines and labor force. Its negative influence on the agricultural environment will be highlighted. Moreover, the increase of the rural elderly population's dependency ratio and lower agricultural profit enhances the negative effect of the insufficient agricultural labor resources. From the perspective of disposable income per capita for rural residents, in 2015, the proportion of agricultural household business income to total family income was $28 \%$ and $27.7 \%$ in Jiangxi and Guizhou, respectively, and 23.9\% in Fujian (the three datasets are from the "Jiangxi Statistic Yearbook 2016", the "Guizhou Statistic Yearbook 2016", and the "Fujian Statistic Yearbook 2015", respectively. The yearbook after 2015 is unavailable in Fujian. Due to statistical indicators, the data of the three provinces cannot be reflected over a long time series). This implies that agricultural income is no longer the main source of rural income. Driven by profit maximization, the majority of the rural labor force chooses to become migrant workers to obtain non-agricultural income. This lowers agricultural investment, which is also less profitable.

Table 1. The agricultural labor force and rural elderly population dependency ratio.

\begin{tabular}{ccccccc}
\hline \multirow{2}{*}{ Year } & \multicolumn{3}{c}{ Agricultural Labor Force Scale (Ten Thousand) } & \multicolumn{3}{c}{ Rural Elderly Population Dependency Ratio (\%) } \\
\cline { 2 - 6 } & Fujian & Jiangxi & Guizhou & Fujian & Jiangxi & Guizhou \\
\hline 1990 & 784.9 & 1193.1 & 1285.5 & - & - & - \\
1995 & 777 & 1071.7 & 1362.8 & - & - & - \\
2000 & 768.1 & 960.9 & 1379.9 & - & - & - \\
2001 & 760.4 & 949.6 & 1368.3 & 12.4 & 10.3 & 9.4 \\
2002 & 756.6 & 964.5 & 1353.9 & 13.1 & 11.3 & 9.4 \\
2003 & 744.8 & 910.7 & 1322.1 & 13.7 & 11.0 & 10.9 \\
2004 & 722.7 & 907.7 & 1288.5 & 14.2 & 11.6 & 10.7 \\
2005 & 699.7 & 907.5 & 1268.1 & 15.0 & 13.9 & 13.5 \\
2006 & 668.6 & 907.4 & 1247.1 & 14.2 & 13.6 & 13.4 \\
2007 & 637.5 & 900.8 & 1203.6 & 15.9 & 13.8 & 12.8 \\
2008 & 636.6 & 900.1 & 1202.1 & 16.3 & 12.9 & 12.4 \\
2009 & 626.3 & 892.6 & 1207.1 & 15.6 & 12.0 & 15.1 \\
2010 & 623.7 & 888.6 & 1188.3 & 13.6 & 12.0 & 16.7 \\
2011 & 620.4 & 870.5 & 1165.3 & 15.6 & 11.9 & 15.6 \\
2012 & 614.9 & 841.0 & - & 15.9 & 12.9 & \\
\hline
\end{tabular}

Notes: (1) All data are collated and calculated according to the Fujian Statistic Yearbook, Jiangxi Statistic Yearbook, and Guizhou Statistic Yearbook [41-43]. Due to the time lag in statistics data in China, through open channels, the authors can only obtain the 2015 statistical yearbook, which contains data for 2014. Moreover, the statistical caliber and measurement basis of some variables are inconsistent in the statistical yearbooks of Fujian, Guizhou, and Jiangxi Provinces. Meanwhile, some data in 2013 and 2014 was missing. Considering data availability, the data in this table are only available until 2012 in order to ensure data consistency. (2) The definition of the elderly in China is the population group that is over 65 years old. 


\subsection{Structural Adjustment of Agriculture}

The acceleration of labor transfer and increase in agricultural labor costs cause changes in agricultural labor resources. The different adaptive behaviors adopted by farmers are always closely related to the feasibility of agricultural factor substitution and planting structural adjustment $[6,43]$. Compared to cash and feed crops, grain crops are less profitable, comparatively, given the ease of mechanization [6] and mature technological supply. In practice, substitution constraints exist when labor is replaced with machinery-namely fitness and cost of substitution. The structural adjustment of agriculture in different areas is also restricted by resource endowment.

In Fujian, Jiangxi, and Guizhou (Figure 1), the terrain is dominated by hills and mountains. Moreover, with numerous plots of land and small plot areas, it is difficult to operate agricultural machinery there (at present, agricultural machinery mainly consist of large devices, which are usable on flat, open fields. Most of them are unable to operate effectively in hilly and mountainous areas. When medium and small agricultural machinery are usable in hilly and mountainous areas, the influence of increasing labor cost on grain production will also be reduced). The structural adjustment of grain crops in Jiangxi Province was the slowest: both wheat and beans decreased, while the sown area of rice, corn, and potato increased. The rice-planting area in Fujian Province declined the most steeply, with a decline of 707.8 thousand hectares from 1990 to 2014. Corn, bean, and potato in Guizhou Province increased the fastest. With an increase of 1.3 times, the sown area for potato increased from 410.3 thousand hectares in 1990 to 944.5 thousand hectares in 2014. The wheat-sown area declined in all three provinces. From the perspective of the structural adjustment of different crops, the sown area for vegetables increased in Fujian, Jiangxi, and Guizhou by 475.5 thousand hectares, 303.1 thousand hectares, and 711.3 thousand hectares from 1990 to 2014, respectively. Guizhou saw the greatest increase in the sown area for vegetables. The planted areas for orchards increased in all three provinces, with increases of 316.5 thousand hectares, 243.5 thousand hectares, and 238.6 thousand hectares from 1990 to 2014 in Jiangxi, Fujian, and Guizhou, respectively. The planted areas for tea increased in Guizhou and Fujian.

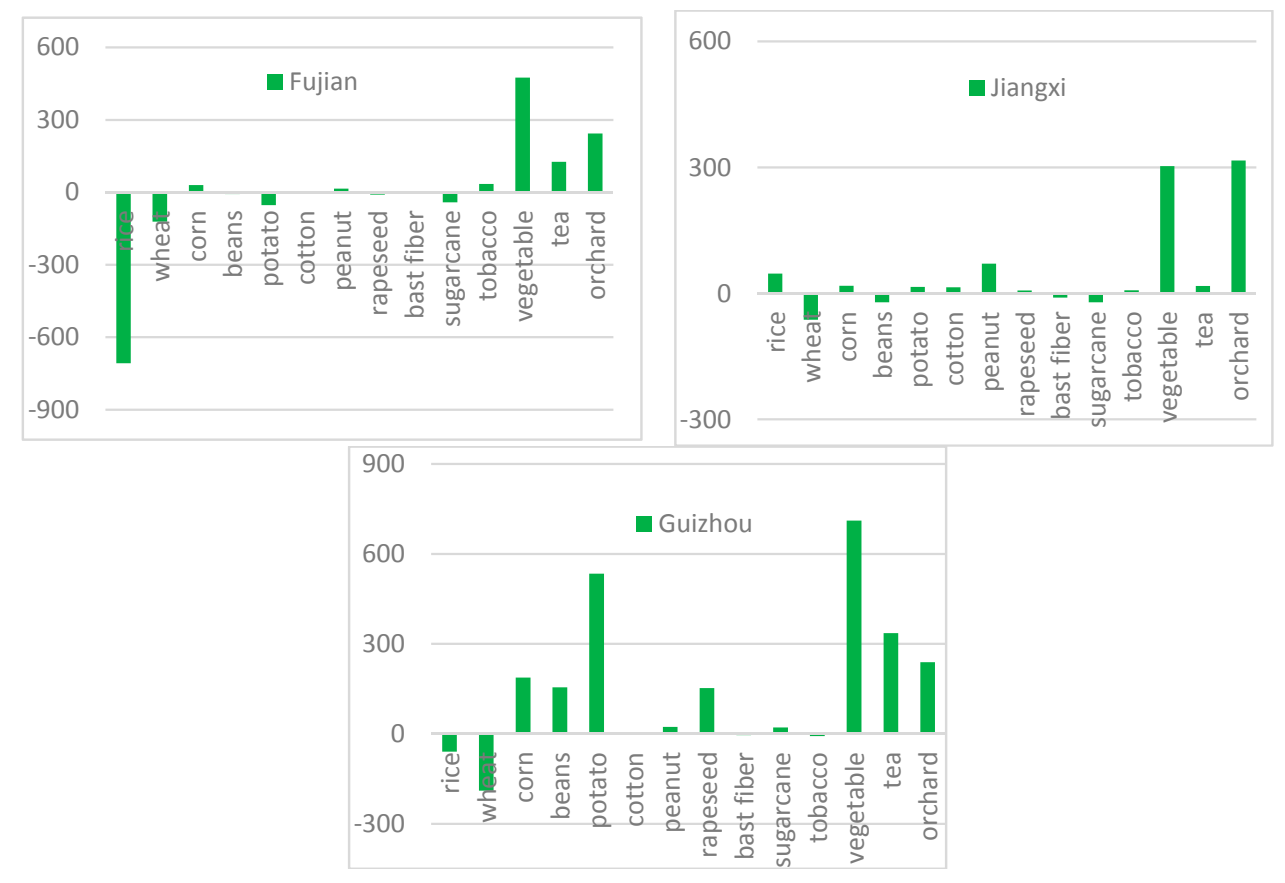

Figure 1. Adjustment in planting structure in Fujian, Jiangxi, and Guizhou from 1990 to 2014 (thousands of hectares).

From the perspective of yield (Table 2), that for vegetables in Fujian was the most advantageous, while in Jiangxi, it was for grains. Moreover, the comparative advantage of fruit yield alternated among 
the three provinces. Before 1990-2000, the fruit yield in Guizhou was comparatively advantageous, while during 2000-2010, the greatest advantage was in Fujian, and after 2010, that in Jiangxi was comparatively advantageous. The yields of grain, vegetables, and fruits per hectare were relatively similar for Fujian and Jiangxi, while those in Guizhou were clearly lagging behind the other two, especially for fruit. The fruit yield per hectare in Guizhou was $7101 \mathrm{~kg}$ less than in Fujian, and $8027 \mathrm{~kg}$ less than in Jiangxi.

Table 2. Yield per hectare of major crops ( $\mathrm{kg} /$ hectare).

\begin{tabular}{cccccccccc}
\hline \multirow{2}{*}{ Year } & \multicolumn{3}{c}{ Grain Yield } & \multicolumn{3}{c}{ Vegetable Yield } & \multicolumn{3}{c}{ Fruit Yield } \\
\cline { 2 - 10 } & FJ & JX & GZ & FJ & JX & GZ & FJ & JX & GZ \\
\hline 1990 & 4230 & 4481 & 2835 & 18,519 & 18,574 & 15,962 & 2540 & 2660 & 7106 \\
1995 & 4560 & 4579 & 3313 & 18,313 & 18,560 & 16,872 & 4496 & 1795 & 5102 \\
2000 & 4676 & 4862 & 3685 & 21,577 & 19,666 & 17,591 & 6323 & 1492 & 7726 \\
2005 & 5060 & 5268 & 3748 & 22,190 & 21,080 & 18,498 & 8705 & 4404 & 8073 \\
2006 & 5158 & 5347 & 3660 & 22,205 & 23,280 & 17,742 & 9139 & 5328 & 9166 \\
2007 & 5288 & 5402 & 3901 & 21,650 & 21,323 & 18,775 & 9643 & 6437 & 9061 \\
2008 & 5390 & 5472 & 3966 & 21,881 & 21,152 & 19,335 & 10,221 & 7619 & 8575 \\
2009 & 5418 & 5556 & 3914 & 22,184 & 21,358 & 20,047 & 11,989 & 8731 & 8504 \\
2010 & 5460 & 5371 & 3659 & 22,298 & 21,399 & 19,294 & 11,989 & 7953 & 8134 \\
2011 & 5484 & 5624 & 2870 & 23,897 & 21,768 & 19,416 & 12,950 & 15,214 & 7575 \\
2012 & 5489 & 5672 & 3534 & 24,183 & 22,157 & 19,378 & 13,250 & 14,544 & 7653 \\
2013 & 5527 & 5733 & 3303 & 24,500 & 22,310 & 19,176 & 13,804 & 15,741 & 7353 \\
2014 & 5569 & 5797 & 3628 & 24,885 & 22,932 & 17,587 & 14,593 & 15,519 & 7492 \\
\hline
\end{tabular}

Note: All data are collated and calculated from the Fujian Statistic Yearbook, Jiangxi Statistic Yearbook, and Guizhou Statistic Yearbook [41-43].

\subsection{Application of Agricultural Chemicals}

Table 3 presents the details on the agricultural chemicals applied to sown areas per hectare. From 1990-2014, the fertilizer applied to sown areas per hectare in Fujian and Jiangxi increased from 0.278 and 0.145 tons per hectare to 0.532 and 0.256 tons per hectare, with increases of 0.914 times and 0.434 times, respectively. That in Guizhou increased from 0.108 tons per hectare in 1990 to 0.181 tons per hectare in 2013. The application of pesticides increased rapidly, as well. Pesticides applied in sown areas per hectare in Fujian increased from 0.011 to 0.024 tons per hectare in 2014, with an increase of 1.182 times. From the observed data, those in Jiangxi and Guizhou increased faster: in 2013, in Jiangxi pesticide application increased $200 \%$ compared to that in 1990 , while pesticide application Guizhou increased by the same proportion. The inefficient and over use of agricultural chemicals is one of the key factors causing environmental pollution in agricultural production and is contrary to agricultural green production.

Table 3. Agricultural chemicals applied in sown area per hectare (ton/hectare).

\begin{tabular}{cccccccccc}
\hline \multirow{2}{*}{ Year } & \multicolumn{3}{c}{ Fujian } & & & Jiangxi & & \multicolumn{2}{c}{ Guizhou } \\
\cline { 2 - 9 } & Fertilizer & Pesticide & Film & Fertilizer & Pesticide & Film & Fertilizer & Pesticide & Film \\
\hline 1990 & 0.278 & 0.011 & - & 0.145 & 0.006 & 0.000 & 0.108 & 0.001 & - \\
1995 & 0.370 & 0.017 & 0.003 & 0.188 & 0.007 & 0.002 & 0.145 & 0.002 & 0.002 \\
2000 & 0.442 & 0.019 & 0.004 & 0.189 & 0.009 & 0.003 & 0.152 & 0.002 & 0.003 \\
2005 & 0.510 & 0.023 & 0.007 & 0.243 & 0.014 & 0.005 & 0.161 & 0.002 & 0.004 \\
2006 & 0.546 & 0.025 & 0.009 & 0.247 & 0.014 & 0.005 & 0.180 & 0.002 & 0.004 \\
2007 & 0.554 & 0.026 & 0.011 & 0.253 & 0.017 & 0.004 & 0.184 & 0.002 & 0.004 \\
2008 & 0.535 & 0.026 & 0.012 & 0.249 & 0.018 & 0.005 & 0.180 & 0.003 & 0.004 \\
2009 & 0.535 & 0.026 & 0.012 & 0.253 & 0.018 & 0.005 & 0.181 & 0.003 & 0.004 \\
2010 & 0.533 & 0.026 & 0.012 & 0.252 & 0.020 & 0.005 & 0.177 & 0.003 & 0.005 \\
2011 & 0.529 & 0.026 & 0.012 & 0.257 & 0.018 & 0.005 & 0.187 & 0.003 & 0.005 \\
2012 & 0.534 & 0.026 & 0.012 & 0.256 & 0.018 & 0.005 & 0.189 & 0.003 & 0.006 \\
2013 & 0.526 & 0.025 & 0.013 & 0.255 & 0.018 & - & 0.181 & - & - \\
2014 & 0.532 & 0.024 & 0.013 & 0.256 & - & - & - & - \\
\hline
\end{tabular}

Note: All data are collated and calculated from the Fujian Statistic Yearbook, Jiangxi Statistic Yearbook, and Guizhou Statistic Yearbook [41-43]. 


\section{Theoretical framework}

\subsection{Mechanism Analysis}

The reason for environmental problems in agriculture is that the changes in technology and systems lags behind those in resource endowment. According to the theory of induced institutional innovation [6-8], the change in relative resource scarcity will induce adaptive technology and systems to save relatively scarce, but frequently used, resources $[10,12,44]$. Among the inputs of agricultural factors, land, capital, and labor are mutually substitutable within certain ranges $[9,10,45,46]$. In Fujian, Jiangxi, and Guizhou, labor transfer of agricultural continues to accelerate. While the changes of technology and systems lag the change of agricultural labor resources, rational farmers will adjust adaptively (Figure 2).

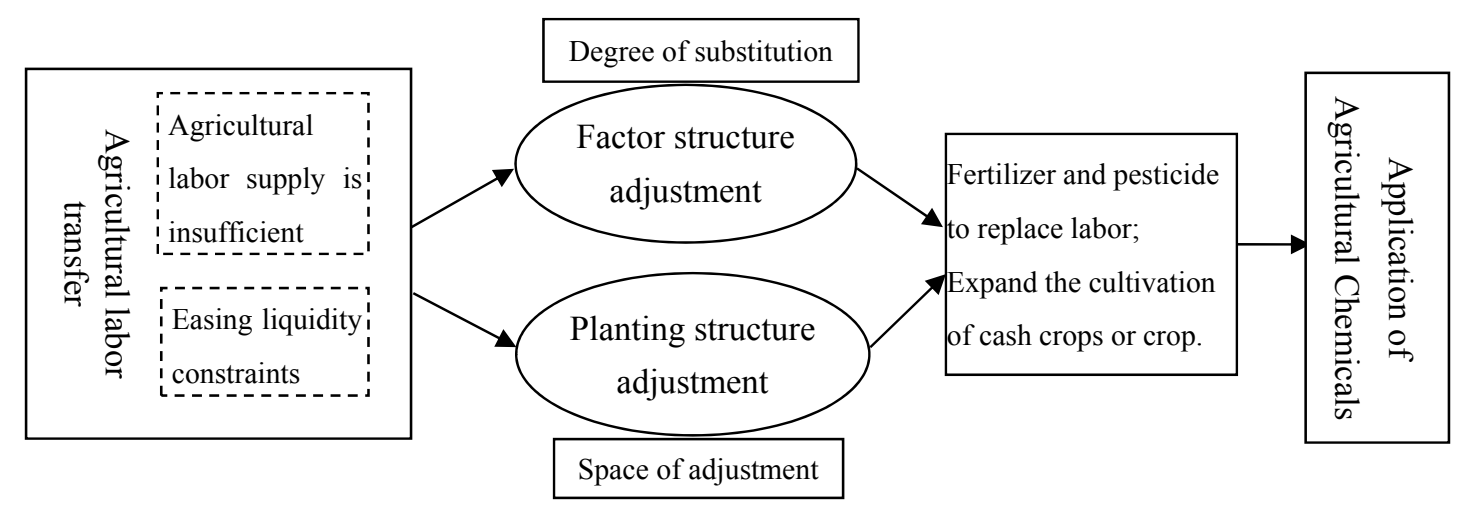

Figure 2. Influencing mechanism of labor transfer and adjustment structure of agricultural on the application of agricultural chemicals.

First, agricultural labor transfer restricts rural labor supply. With lower profits for agriculture and increasing rural labor costs, farmers will adjust the structure of factor inputs, turning to machinery operations, or applying fertilizers and pesticides, to substitute the labor force needed for field management. However, mechanical substitution is constrained by the terrain. Compared with plain areas, hilly and mountainous areas are not suitable for machinery operation due to the small and dispersed land plots. Moreover, agricultural machinery typically consist of large items. When there are few agricultural machines designed for small-scale or elderly farmers, or when machinery operation is expensive, machinery substitution is restricted. Consequently, rational farmers will choose fertilizers and pesticides, which are less restrictive and tend to reduce fertilization times and increase fertilization amount, to ease labor constraints. In addition, with high agricultural production risks and farmers' risk aversion, increasing the inputs of fertilizers and pesticides becomes an important means for farmers-especially small-scale farmers-to avoid risks.

Second, labor transfer induces farmers to adjust planting structures to optimize the allocation of agricultural production factors. In general, farmers will turn to the planting of profitable cash or feed crops, which require less labor and more fertilizers. Moreover, in order to reduce labor input, they grow more grain crops for which it is easy to operate machines. Further, they turn from labor-intensive crop farming to the capital-intensive breeding industry. Of course, the structural adjustment of agriculture is restricted by the adjustable space, especially for vast rural areas far away from cities. It is difficult for farmers to adjust the planting structure flexibly according to market demand and price changes, since there will be no change in planting varieties and planting structure in the short run due to the limited market demand and sales radius.

Finally, an increase of non-agricultural income brought by labor transfer would ease the liquidity constraints. It enhances farmers' ability to pay for agricultural machinery, production services, and agricultural production factors. While mechanical operations and production service are unavailable 
due to the complex terrain, rational farmers would choose to increase the application of fertilizers and pesticides (at present, production service in China is mainly supplied by large agricultural machinery, which requires mechanization and concentrated land plots to gain effect of economies of scale and reduce costs. Hilly and mountain terrain also restricts its service supply). Moreover, compared to grain crops, non-grain crops are more profitable and their production is more sensitive to capital liquidity constraints. The relaxation of liquidity constraints is beneficial to increasing non-grain crops and encouraging farmers to grow more value-adding cash crops. However, it is difficult to apply mechanical operations to non-grain crops, as they require more labor and fertilizers.

\subsection{Model}

Based on the above analysis, in order to analyze the impact of labor transfer and structural adjustment of agriculture on the application of agricultural chemicals, we introduce the following panel data model:

$$
Y_{i t}=\alpha_{0}+\alpha_{i}+\gamma_{t}+\beta_{1} X_{1 i t}+\beta_{2} X_{2 i t}+\beta_{3} X_{3 i t}+\beta_{4} X_{4 i t}+\beta_{5} X_{5 i t}+\beta_{6} X_{6 i t}+\beta_{7} X_{7 i t}+\beta_{8} X_{8 i t}+\varepsilon_{i t}
$$

where $i$ represents the province, $t$ is the year, $\alpha_{i}$ are the differences among provinces, and $\gamma_{t}$ the differences in time. $Y_{i t}$ is the dependent variable, which reflects the application of agricultural chemicals and is represented by fertilizers and pesticides applied to the sown area per hectare. $X_{1 i t}$ and $X_{2 i t}$ are two important main variables. The variable of labor transfer is represented by the quantity of the rural labor force over time $\left(X_{1 i t}\right)$, and the structural adjustment of agriculture is represented by the ratio of sown area of non-grain crops (cash and feed crops) to the total sown area $\left(X_{2 i t}\right)$. $X_{3 i t}$ represents the retail price of grain, $X_{4 i t}$ represents the retail price of fertilizers, $X_{5 i t}$ represents the retail price of pesticides, $X_{6 i t}$ represents the disposable income per capita of rural residents, $X_{7 i t}$ represents the non-agricultural wages, and $X_{8 i t}$ represents the min-tractors. $\varepsilon_{i t}$ is the random disturbance term. To eliminate the impact of dimension, we use the log transform of the explanatory variables excluding the variables reflecting the adjustment of agricultural structure and the explained variable.

According to the theory of the Cobweb model, farmers choose appropriate combinations of factor inputs based on the factor price $[47,48]$ and make decisions based on the price of agricultural products over the last period. Considering data availability, this paper selects the production price index of fertilizer and pesticides and the retail price of grain. All data are converted to the 1995 benchmark price. Machinery is a strong alternative to labor, but large agricultural machinery is costly and unavailable in hilly and mountainous areas, so it is impractical for small-scale farmers to use them widely. As such, the agricultural mechanization level of Fujian, Guizhou, and Jiangxi Provinces is measured by mini-tractors, which are easy to operate in hilly and mountainous areas. Moreover, the higher the rural residents' per capita disposable income is (Cai F. (2016) pointed out that, 65.6\% of farmers' net income was unrelated to agriculture in 2012 [49]), the stronger their non-agricultural working ability, and the less dependent they are on agricultural income. The rapid increase in non-agricultural wages is the main reason for rural labor transfer. Farmers who are unable to obtain stable non-agricultural income will engage in part-time non-agricultural employment. Agricultural labor supply will, thus, be reduced, and more fertilizer and pesticides will be applied. To eliminate the effect of inflation, the variables of rural residents' per capita disposable income and non-agricultural wages are deflated by the consumer price index. It is unfortunate that some data were missing in 2013 and 2014. Additionally, retail price index data, which is included as the explanatory variable, is not kept in statistical yearbooks before 1995. Considering the data availability, the study period in the empirical analysis is 1995-2012 in order to ensure data consistency.

\section{Results}

Table 4 presents the descriptive statistics of each variable. Fertilizers applied in sown area per hectare are $287.58 \mathrm{~kg}$ and that for pesticides are $12.29 \mathrm{~kg}$. The ratio of sown area of non-grain crops to 
total sown area is 0.29 , which is relatively low. Agricultural production is dominated by growing food crops in each province. The agricultural labor force scale is still large. The average non-agricultural wage is $15,546.64$ yuan, and rural per capita disposable income is 3687.51 yuan. The number of mini-tractors is $121,570.3$ (unit: set).

Table 4. Descriptive statistics of each variable.

\begin{tabular}{cccc}
\hline Variables & Definition & Mean & S.D \\
\hline Fertilizers applied in sown area per hectare & $1000 \mathrm{~kg} / \mathrm{ha}$ & 0.29 & 0.142 \\
Pesticides applied in sown area per hectare & $1000 \mathrm{~kg} / \mathrm{ha}$ & 0.01 & 0.008 \\
Ratio of sown area of non-grain crops to total sown area & $\%$ & 0.29 & 0.053 \\
Agricultural labor force scale & Ten thousand people & 978.08 & 246.41 \\
Retail price index of grain & benchmark price in 1995 & 84.5 & 22.72 \\
Retail price index of fertilizers & benchmark price in 1995 & 83.94 & 23.86 \\
Retail price index of pesticides & benchmark price in 1995 & 86.24 & 11.57 \\
Non-agricultural wages & Yuan (benchmark price in 1995) & 3687.51 & 2103.12 \\
Mini-tractors & Yuan (benchmark price in 1995) & $15,546.64$ & 8979.41 \\
Disposable income per capita & Set & $121,570.3$ & $102,436.2$ \\
\hline
\end{tabular}

Note: (1) All data are collated and calculated from the Fujian Statistical Yearbook, Jiangxi Statistical Yearbook, and Guizhou Statistical Yearbook [41-43]; (2) To eliminate the effect of inflation, the variables of disposable income per capita of rural residents and non-agricultural wages are deflated by the consumer price index. Taking year 1995 as the benchmark, the authors set the price in 1995 at 100.

Stata 13.0 (StataCorp LLC, College Station, TX, USA) was used to analyze the panel data. However, a Hausman test is first essential to determine whether to adopt a fixed or random effects model. Table 5 shows that the values of the Hausman test values are 32.14 and 42.15 , respectively, and both original hypotheses of the random effect were rejected at $1 \%$. It implies the regression results of a fixed effects model are preferable.

Table 5. Analysis of regression results.

\begin{tabular}{ccccc}
\hline Variables & \multicolumn{2}{c}{ Fertilizers } & \multicolumn{2}{c}{ Pesticides } \\
\cline { 2 - 5 } & Coef. & S.E & Coef. & S.E \\
\hline Agricultural labor force scale & $-0.312^{* * *}$ & 0.100 & $-0.036^{* * *}$ & 0.009 \\
Ratio of sown area of non-grain crops to total sown area & $0.304^{* *}$ & 0.127 & $0.027^{* *}$ & 0.011 \\
Retail price index of grain & $-0.077^{* * *}$ & 0.025 & -0.000 & 0.002 \\
Retail price index of fertilizers & 0.028 & 0.024 & - & - \\
Retail price index of pesticides & - & - & -0.004 & 0.004 \\
Disposable income per capita of rural residents & -0.030 & 0.026 & -0.001 & 0.002 \\
Non-agricultural wages & $0.178^{* * *}$ & 0.056 & $0.020^{* * *}$ & 0.006 \\
Mini-tractors & $-0.143^{* *}$ & 0.062 & $-0.012^{*}$ & 0.007 \\
Constant term & $2.147^{* *}$ & 0.803 & $0.234^{* * *}$ & 0.071 \\
Hausman test & Chi2(2)=32.14*** & Chi2(2) $=42.25^{* * *}$ \\
F test & $\mathrm{F}(2,39)=70.72^{* * *}$ & $\mathrm{~F}(2,39)=5.25^{* * *}$ \\
$\mathrm{R}^{2}$ & \multicolumn{2}{c}{0.870} & 0.857 \\
\hline
\end{tabular}

Note: (1) In this paper, the value of chemical fertilizers and pesticides applied to the sown area per hectare is between 0 and 1 . However, the values of most explanatory variables are very large. In order to reduce the absolute value of the data and make the data more stable, we use the log transform of the explanatory variables, and it will not change the nature and correlation of the data [50]. The variables reflecting the adjustment of agricultural structure are excluded; (2) ******* represent significance at the $1 \%, 5 \%$, and $10 \%$ levels, respectively.

The agricultural labor force scale has a statistically significantly negative effect on the amount of fertilizers and pesticides applied to the sown area at the $1 \%$ significance level. Specifically, the larger the agricultural rural labor force scale, the more flexible the labor resources required for agricultural production. Agriculture production bears the feature of seasonality. There is a great demand for the labor force during the busy season, and labor costs increase due to labor scarcity. The larger the agricultural labor force scale, the less restricted the labor supply during the busy season, and the less fertilizer and pesticide applied. From the perspective of the structural adjustment of agriculture, 
there is a statistically significant positive influence of the ratio of the sown area of non-grain crops to the total sown area on the amount of fertilizers and pesticides used at the $5 \%$ significance level. As the sown areas of cash or feed crops increase, fertilizers and pesticides applied to them increase accordingly. The labor force required for non-grain crops is lower than that required for grain crops. Labor transfer causes increasing labor costs. As a result, farmers turn to growing more profitable non-grain crops, and are more motivated to apply fertilizer and pesticides in order to achieve higher yields. However, doing so affects product quality and causes agricultural pollution, which is not conducive to the sustainable development of agriculture.

Based on data availability, the retail price index of grain (rice, wheat, and corn) in the last period was selected to represent the product price in the last period. There is a statistically significant negative impact of the retail price index of grain in the previous period on the amount of fertilizer applied to the sown area, and a negative, but statistically insignificant, impact on the amount of pesticides applied to the sown area. For large-scale farmers, if they choose to grow cash or feed crops, they will not easily change their planting decisions in the short run. Small-scale farmers, who are influenced by marketing channels and sales radii in the pursuit of profit maximization, are more sensitive to price changes and would make planting decision adjustments. With the increase of grain-crop price, small-scale farmers are more motivated to grow grain crops. Further, there is a negative, but statistically insignificant, impact of the retail price index of fertilizers and pesticides on the application of fertilizers and pesticides in the current period. Farmers would buy fewer fertilizers and pesticides due to the increasing prices.

There is a statistically significantly negative impact of the mini-tractors on the application of fertilizers and pesticides at the significance levels of $5 \%$ and $10 \%$, respectively. Presently, agricultural production services are mainly supplied by large agricultural machinery, which requires mechanization and concentrated land plots to gain the effect of economies of scale and reduce operation costs. However, Fujian, Jiangxi, and Guizhou are mainly composed of hilly and mountainous areas, meaning the terrain restricts agricultural service supply. The mini-tractors reflect machinery substitution for labor to some extent. The more mini-tractors farmers own, the stronger their ability of coping with rural labor transfer and rising labor costs. Generally, machinery, fertilizers, and pesticides are substitutable and complementary. There is a statistically significantly positive impact of non-agricultural wages on the amount of fertilizers and pesticides applied to sown areas at the $1 \%$ significance level. The higher non-agricultural wages are, the more motivated farmers are to go out to engage in non-agricultural employment, and farmers will spend less time on agricultural production. As a result, extensive management will be popular, and more fertilizers and pesticides will be used. There is a negative, but statistically insignificant, impact of the disposable income per capita of rural residents on the amount of fertilizers and pesticides applied to the sown area per hectare. The higher the rural residents' per capita disposable income, the less dependent they are on agricultural income. Moreover, the strong demand for green ecological products helps reduce the application of fertilizers and pesticides.

\section{Conclusions and Discussion}

As an important part of the construction of an ecological civilization, reducing the application of agricultural chemicals, is key to promoting the green and sustainable development of agriculture. Focusing on the two main characteristics of current agricultural development-namely labor transfer and structural adjustment of agriculture-this paper makes a comparative analysis on labor transfer, the structural adjustment of agriculture, and the application of agricultural chemicals in Fujian, Jiangxi, and Zhejiang. The analysis is based on the statistical yearbook data from provinces which became the first national ecological civilization pilot zones in China. Furthermore, using panel data from 1995-2012, the paper empirically analyzes the influence of land transfer and structural adjustment of agriculture on the application of fertilizers and pesticides. The conclusions are as follows: Firstly, the amplitudes of the agricultural labor force in Fujian, Guizhou, and Jiangxi have decreased successively. The structural adjustment of grain crops is the slowest in Jiangxi, while the sown area of cash crops, such as vegetables, 
increases the fastest in Guizhou. The increase of horticultural plants, such as orchards, is the most obvious in Jiangxi. Moreover, the influence of the agricultural labor force scale on the amount of fertilizers and pesticides is statistically significantly negative. If the sown area of cash crops or feed crops increases, the amount of fertilizer and pesticide would increase accordingly. Secondly, the influence of the agricultural labor force scale on the application of fertilizers and pesticides used on sown areas is statistically significant negative. This conclusion is consistent with Zhang et al. [51], who concluded that the more time used for agricultural production, the less fertilizer that is applied. The ratio of the sown area of non-grain crops to total sown area has a positive effect on the application of fertilizers and pesticides. A study also reveals that vegetables and fruits have become the major drivers of fertilizer consumption, and the trends in demand for fruits and vegetables have been more lucrative than grains for producers, driving farmers to increase their use of chemical fertilizers [52].

With the continuous development of urbanization, the shift of the rural labor force to non-agriculture industries is inevitable. In response to the impact of this change on the application of agricultural chemicals, the government should increase subsidies or benefits to farmers who use organic fertilizer. Additionally, the organic fertilizer resources are abundant in China. The total organic nutrient storage reached $63.6 \mathrm{Mt}$ in 2006 (pure nutrients), but only 57\% was returned to the field [53]. Increasing the efficiency of returning crop residues and manures back to the field can alleviate our excessive dependence on chemical fertilizers. In the process of the structural adjustment of agriculture, concerning the upgrading of consumers' consuming structure for healthy agricultural products, the government should accelerate agricultural technology promotion and raise farmers' awareness of scientific fertilization. In addition, practices, such as integrated soil-crop systems management, are essential for vegetables and fruits.

A fact that cannot be ignored in China is that the circulation market for agricultural land management rights is experiencing a fast development. New agricultural business entities have become the main force of China's agricultural modernization. During this process, the government should continue to improve the stability of land management rights and raise the long-term expectation for land. To maximize agricultural profits, new agricultural business entities are more likely to have higher expectations to adjust the structures of investments, and to put more effort towards the use of organic manure [39].

Furthermore, we also suggest accelerating the development of smaller agricultural machinery that can be used for smaller land areas and by elderly people, especially in hilly regions in China. A study reveals that promoting the mechanization to substitute the labor force can also compensate for labor shortages, thus curbing the excessive $\mathrm{N}$-fertilizer application [54]. The aging trend of the agricultural labor force in China is aggravating year by year, and the phenomenon is especially true in hilly and mountainous areas [55]. Therefore, developing such machinery can incentivize the mechanization of agricultural production in order to improve the effective substitution of machinery for labor and, thus, reduce the application of chemical fertilizers.

However, due to the time lag in statistical data in China, through open channels, the authors can only obtain the 2015 statistical yearbooks, which contain data for 2014. It is regrettable that the latest data is unavailable. The effect before and after the implementation of the policy and the substitution effect of chemical fertilizer can be further studied in the future. Lastly, simulation on the changes in labor transfer and agricultural structural adjustment, and quantitative estimation of the changes' impact on agricultural chemicals, are worth exploring in the future.

Author Contributions: H.L., H.X., and J.J. had the original idea for the study; H.L. and Q.C. were responsible for data collecting, and carried out the analyses; All the authors drafted the manuscript, and approved the final version.

Funding: This study was supported by the Major Program of the National Social Science Foundation of China (no. 15ZDB159); the National Natural Science Foundation of China (no. 41561040); the Academic and Technical Leaders Funding Program for Major Disciplines in Jiangxi Province (no. 20172BCB22011); the Sixty-second Batch of China Postdoctoral Science Foundation Funding (no. 2017M622097); the Humanities and Social Sciences Research Project of Jiangxi Universities in 2017 (no. JJ17205); Jiangxi Social Science Planning Youth Doctoral 
Fund Project in 2017 (no. 17BJ39); Jiangxi Province Postdoctoral Daily Fund in 2017 (no. 2017RC39); and the Postdoctoral Funded Project of Jiangxi University of Finance and Economics in 2017.

Conflicts of Interest: The authors declare no conflict of interest

\section{References}

1. Wei, X.; Li, S.P.; Zhang, Z.C.; Cui, C.X. Analysis on farmers' agricultural non-point source pollution-based on land property right system. Rural Econ. 2012, 5, 108-112. (In Chinese)

2. Lu, H.; Xie, H.L. Impact of changes in labor resources and transfers of land use rights on agricultural non-point source pollution in Jiangsu Province, China. J. Environ. Manag. 2018, 207, 134-140. [CrossRef] [PubMed]

3. Tollefson, J. Intensive farming may ease climate change. Nature 2010, 465, 853. [CrossRef] [PubMed]

4. Gong, P. China needs no foreign help to feed itself. Nature 2011, 474, 7. [CrossRef] [PubMed]

5. National Health and Family Planning Commission Floating Population Division. Report on China's Migrant Population Development; China Population Publishing House: Beijing, China, 2016. (In Chinese)

6. Hayami, Y.; Ruttan, V.W. Agricultural Development: An International Perspective; The Johns Hopkins Press: Baltimore, MD, USA; London, UK, 1971.

7. Ruttan, V.W.; Hayami, Y. Toward a theory of induced institutional innovation. J. Dev. Stud. 1984, 20, $203-223$. [CrossRef]

8. Ruttan, V.W.; Hayami, Y. Induced Innovation Theory and Agricultural Development. Can Economic Growth Be Sustained: The Collected Papers of Vernon W; Oxford University Press: England, UK, 2011.

9. Cai, F.; Wang, M. Reconsideration on rural surplus labor forces and some relevant facts-with application of fact retro-assumption method. Chin. Rural Econ. 2007, 1, 4-12. (In Chinese)

10. Zheng, X.Y.; Xu, Z.G. Endowment restriction, factor substitution and induced technological innovation: A case research on the grain producing mechanization in China. China Econ. Q. 2017, 1, 45-66. (In Chinese)

11. Lin, Y.; Tian, Z. General experience and policy implications of our country's agricultural technological change. Comp. Econ. Soc. Syst. 1990, 2, 10-18.

12. Hayami, Y.; Ratan, V.M. The International Analysis of Agricultural Development; Social Sciences in China: Beijing, China, 1996.

13. Lin, J.; Li, D.X. Non-agricultural employment and grain production: Substitutional or complementaryBased on the analysis of major grain production areas from the perspective of farmers. Chin. Rural Econ. 2013, 9, 54-62. (In Chinese)

14. Wang, C.G.; Rada, N.; Qin, L.J.; Pan, S.W. Impacts of migration on household production choices: Evidence from China. J. Dev. Stud. 2014, 50, 413-425. [CrossRef]

15. Chang, H.; Mishra, A.K. Chemical usage in production agriculture: Do crop insurance and off-farm Work play a part? J. Environ. Manag. 2012, 105, 76-82. [CrossRef] [PubMed]

16. Ebenstein, A.; Zhang, J.; McMillan, M.C. Chemical Fertilizer and Migration in China; America, National Bureau of Economic Research: Cambridge, MA, USA, 2011.

17. Williamson, J.M. The role of information and price in the nitrogen fertilizer management decision: New evidence from the agricultural resource management survey. J. Agric. Resour. Econ. 2011, 36, 552-572.

18. Abdoulaye, T.; Sanders, J.H. Stages and determinants of fertilizer use in semiarid African agriculture: The Niger experience. Agric. Econ. 2005, 32, 167-179. [CrossRef]

19. Calhoun, C. Estimating the distribution of desired family size and excess fertility. J. Hum. Resour. 1989, 24, 709-724. [CrossRef]

20. Horowitz, J.; Lichtenberg, E. Insurance, more hazard, and chemical use in agriculture. Am. J. Agric. Econ. 1993, 75, 926-935. [CrossRef]

21. Jepson, W. A disappearing biome? Reconsidering land-cover change in the Brazilian savanna. Geogr. J. 2005, 171, 99-111. [CrossRef]

22. Li, L.; Wang, C.; Segarra, E.; Nan, Z. Migration, remittances, and agricultural productivity in small farming systems in Northwest China. China Agric. Econ. Rev. 2013, 5, 5-23. [CrossRef]

23. Peng, H.Y.; Shi, Z.T.; Liu, X.Y.; Yu, F. Analysis of crop planting structure and farmers' income and its impact on environment. Environ. Sci. Manag. 2008, 2, 44-48. (In Chinese) 
24. Xin, L.; Li, X.; Tan, M. Temporal and regional variations of China's fertilizer consumption by crops during 1998-2008. J. Geogr. Sci. 2011, 22, 643-652. [CrossRef]

25. Yang, Q.; Yang, S.; Ma, W.; Shi, Z. Space distributing and using of cultivated land in mountains area. Mt. Res. 2005, 6, 6749-6755. (In Chinese)

26. Ying, R.Y.; Zheng, X.Y. Resources endowment, factor substitution and the transformation of agricultural production and operation: Example from food production in Jiangsu and Zhejiang. Issues Agric. Econ. 2013, 12, 15-24. (In Chinese)

27. Gu, T.Z.; Ji, Y.Q.; Zhong, F.N. The source of economies of scale in China's agricultural production. Chin. Rural Econ. 2017, 2, 30-43. (In Chinese)

28. Lv, T.; Ji, Y.Q.; Yi, Z.Y. Economies of scale in plot size of rice production-based on the investigation and analysis of Jintan in Changzhou, Jiangsu Province. J. Agrotechnol. Econ. 2014, 2, 68-75. (In Chinese)

29. Chiodi, V.; Jaimovich, E.; Montesrojas, G. Migration, remittances and capital accumulation: Evidence from rural Mexico. J. Dev. Stud. 2012, 48, 1139-1155. [CrossRef]

30. Dustmann, C.; Kirchkamp, O. The optimal migration duration and economic activities after return migration. J. Dev. Econ. 2002, 67, 351-372. [CrossRef]

31. Konseiga, A. Household migration decisions as a survival strategy: The case of Burkina Faso. J. Afr. Econ. 2007, 16, 198-223. [CrossRef]

32. Mccarthy, N.; Carletto, C.; Kilic, T.; Davis, B. Assessing the impact of massive out-migration on Albanian agriculture. Eur. J. Dev. Res. 2009, 21, 448-470. [CrossRef]

33. Gonzalez-Velosa, C. Essays on Migration and Agricultural Development. Ph.D. Thesis, University of Maryland, College Park, MD, USA, 2011.

34. He, H.R.; Zhang, L.X.; Li, Q. Farmers fertilization behavior and agricultural non-point source pollution. J. Agrotechnol. Econ. 2006, 6, 2-10. (In Chinese)

35. Huang, J.K.; Hu, R.F.; Cao, J.M.; Rozelle, S. Training programs and in-the field guidance to reduce China's overuse of fertilizer without hurting profitability. J. Soil Water Conserv. 2008, 63, 165A-167A. [CrossRef]

36. Long, Y.; Ren, L. The influence of farmland circulation on agricultural non-point source pollution-From the perspective of farmers' behavior. Economist 2016, 8, 81-87. (In Chinese)

37. Zhang, X.S.; Dan, J. On the research of cultivating the New Agricultural Management Entities under the Background of Accelerating the Agricultural Modernization. J. Xiangtan Univ. (Philos. Soc. Sci.) 2014, 3, 17-24. (In Chinese)

38. Zhu, M.; Qi, Z.H.; Wu, L.Y.; Li, X.L.; Tang, S.Y. Empirical analysis on factors of new agricultural business entities' agricultural technology needs-Taking 395 scaled rice farmers in southern Jiangsu province as the example. Chin. Rural Surv. 2015, 1, 30-38. (In Chinese)

39. Ministry of Agriculture. Action Plan of Replacing Fertilizers with Organic Manure; Ministry of Agriculture: Beijing, China, 2017. (In Chinese)

40. Qiu, H.G.; Luan, H.; Li, J.; Wang, Y.J. The influence of risk avoidance to farmers' over application of fertilizers. Chin. Rural Econ. 2014, 3, 85-96. (In Chinese)

41. Statistic Bureau of Jiangxi. Jiangxi Statistical Yearbook; China Statistic Press: Beijing, China, 2016. (In Chinese)

42. Statistic Bureau of Guizhou. Guizhou Statistical Yearbook; China Statistic Press: Beijing, China, 2016. (In Chinese)

43. Statistics Bureau of Fujian. Fujian Statistical Yearbook; China Statistic Press: Beijing, China, 2015. (In Chinese)

44. Liu, Q.; Shumway, C.R. Geographic aggregation and induced innovation in American agriculture. Appl. Econ. 2006, 38, 671-682. [CrossRef]

45. Hu, H.; Yang, Y.B. Research on fertilizer application of farmer households from the perspective of elemental substitution-Based on the rural fixed observation point data from the Ministry of Agriculture of the People's Republic of China. J. Agrotechnol. Econ. 2015, 3, 84-91. (In Chinese)

46. Binswanger, H.P. A cost function approach to the measurement of elasticities of factor demand and elasticities of substitution. Am. J. Agric. Econ. 1974, 377-386. [CrossRef]

47. Chiarell, C. The cobweb model: Its instability and the onset of chaos. Econ. Model. 1988, 5, 377-384. [CrossRef]

48. Song, C.M. Study on fluctuation of pork price under nonlinear and disquilibrium cobweb model. J. Huazhong Agric. Univ. (Soc. Sci. Ed.) 2016, 6, 1-7. (In Chinese)

49. Cai, F. Urbanization should keep pace with agricultural modernization. Beijing Daily 2016, 2, 15. (In Chinese) 
50. Chang, Y.F.; Hong, Y.W.; Naiji, L.; Tian, C.; Hua, H.; Ying, L. Log-transformation and its implications for data analysis. Shanghai Arch. Psychiatry 2014, 26, 105.

51. Zhang, J.; Manske, G.; Zhou, P.Q.; Tischbein, B.; Becker, M.; Li, Z.H. Factors influencing farmers' decisions on nitrogen fertilizer application in the Liangzihu Lake basin, Central China. Environ. Dev. Sustain. 2017, 19, 791-805. [CrossRef]

52. Chen, X.H.; Ma, L.; Ma, W.Q.; Wu, Z.G.; Cui, Z.L.; Hou, Y.; Zhang, F.S. What has caused the use of fertilizers to skyrocket in China? Nutr. Cycl. Agroecosyst. 2018, 110, 241-255. [CrossRef]

53. Li, Y.M.; Yuan, Y.R.; Li, G.X.; Chen, Q.; Zhang, F.S. Present situation and management suggestion of organic waste recycling in China. Chin. Farm. Syst. Res. Prog. 2008, 10, 464-471. (In Chinese)

54. Hu, Y.; Man-de, Z. Farmers behavior influenced by labour force mitigation and food commercialization-Based on the data from 587 households in China. Chin. Econ. Trade 2014, 3, 18-22.

55. He, X.Q. Research on the aging of agricultural labor-Based on rural research in Zhejiang province. Popul. Econ. 2013, 2, 69-77. (In Chinese)

(C) 2018 by the authors. Licensee MDPI, Basel, Switzerland. This article is an open access article distributed under the terms and conditions of the Creative Commons Attribution (CC BY) license (http:/ / creativecommons.org/licenses/by/4.0/). 